\title{
Chemical Literacy: Performance of First Year Chemistry Students on Chemical Kinetics
}

\author{
Muntholib $^{1}$, Suhadi Ibnu' ${ }^{2}$, Sri Rahayu ${ }^{2,}$, Fauziatul Fajaroh ${ }^{2}$, Sentot Kusairi ${ }^{3}$, and Bambang Kuswandi ${ }^{4}$ \\ ${ }^{1}$ Postgraduate Program, Universitas Negeri Malang, Jl. Semarang No. 5 Malang 65145, East Java, Indonesia \\ ${ }^{2}$ Department of Chemistry, Universitas Negeri Malang, Jl. Semarang No. 5 Malang 65145, East Java, Indonesia \\ ${ }^{3}$ Department of Physics, Universitas Negeri Malang, Jl. Semarang No. 5 Malang 65145, East Java, Indonesia \\ ${ }^{4}$ Faculty of Pharmacy, University of Jember, Jl. Kalimantan No. 37 Jember 68121, East Java, Indonesia
}

\section{*Corresponding author:}

email: sri.rahayu.fmipa@um.ac.id

Received: February 17, 2019

Accepted: April 15, 2019

DOI: $10.22146 /$ ijc. 43651

\begin{abstract}
This study aimed to (1) develop and validate a multiple-choice chemical literacy test instrument (MC-CLTI) on chemical kinetics especially on knowledge and competency aspects and (2) conduct a small survey on chemical literacy of first year chemistry students. The development of the instrument involved expert consultation and judgment, validation, and twice trials. The first trial involved 119 first-year chemistry students of regular classes to capture the feasibility of MC-CLTI development. The second trial involved 197 first-year chemistry students, both regular and bilingual classes, to analyze the validity and reliability of the developed instruments. The final form of MCCLTI consists of 30 valid and reliable items (Cronbach's Alpha coefficient $=0.744$ ). The survey was conducted to 71 first-year chemistry students of bilingual classes after they received chemical kinetics lessons conducted using the expository instruction approach. The result showed that the respondents' average chemical literacy score was 63.24 (satisfactory). The implication from this study was discussed.
\end{abstract}

Keywords: chemical literacy; multiple-choice chemical literacy test instrument; chemical kinetics

\section{- INTRODUCTION}

Nowadays, scientific literacy has become one of the main goals of contemporary science education [1-4]. The concept of scientific literacy generally covers three important aspects, namely scientific knowledge, scientific inquiry and the nature of the scientific knowledge produced, and awareness of the interplay between scientific inquiry and the daily life social context [5-8]. As part of science education, chemical education also undergoes changing by placing chemical literacy as the main goals of chemical education.

One consequence of placing chemical literacy as a goal of chemical education is the availability of appropriate assessments, including chemical literacy instruments. For this purpose, several assessment frameworks have been developed [2,4,7,9-10]. In the OECD framework $[2,7,9]$, scientific literacy is divided into four aspects interconnecting each other. These four aspects are context (personal, national and global), scientific knowledge (knowledge of natural world and technology, knowledge of how knowledge is produced, and understanding that underlies the use of scientific procedures); competencies (ability to explain phenomena scientifically, evaluate and design scientific inquiry, and interpret data and evidence scientifically), and attitude (interest in science and technology, valuing scientific approaches to inquiry, and awareness of environmental issues $[2,7,9]$. Whereas according to the Shwartz et al. framework $[4,10]$, chemical literacy covers four aspects, namely (1) knowledge of science and chemical content, (2) chemistry in context, (3) high level learning skills and (4) attitude [4,11]. Compared with the Shwartz et al. framework, the OECD framework is more popular, simple, and explicit.

Several chemical literacy instruments have been developed based on the above frameworks. Shwartz et al.

Muntholib et al. 
[4], for example, have developed various assessment tools including the use of Likert-type scales, open-ended questionnaires, and multiple-choice questionnaires based on their framework and have been used to examine 10$12^{\text {th }}$ grade students' chemical literacy. They argued that chemical literacy is a multi-dimensional and complex term. For them, it was difficult to assess all of the chemical literacy aspects and components using a single instrument. The topics chosen were properties of particulate matter, chemical reactions, the ability to use laws and chemical theories to explain phenomena, and chemical applications in everyday life. Cigdemoglu and Geban [2] have developed an open-ended format of chemical literacy test based on the PISA-2006's assessment framework to examine knowledge and competencies aspects of chemical literacy of $11^{\text {th }}$ grade students on thermochemistry and thermodynamics. For the assessment, students were exposed to a daily live phenomenon. Items about content knowledge and abilities to interpret a given data were asked following the phenomenon. These items measure students' ability to use and handle information about chemistry problems and their ability to use chemistry knowledge and skills to comprehend daily life phenomena. Thummathong and Thathong [11] have developed multiple-choice and written forms of test instruments on basic chemistry contents to examine undergraduate engineering students' chemical literacy. The test was developed based on the components of chemical literacy contained in several assessment frameworks [4,12-13]. Cigdemoglu et al. [9] have developed an open-ended form of test instruments on acid-base concepts to examine first year university students' chemical literacy. The test followed the PISA2006's assessment framework. However, there is no knowledge and competencies aspects of chemical literacy test whose type is multiple-choice and the content knowledge is chemical kinetics.

It is generally accepted that the most efficient test for identifying students' conceptions is a multiple-choice test [14]. This type of test is easy to use, efficient for large respondents, and simple in data analysis. In addition, the use of this test also requires a short time. Many multiplechoice tests have been developed. Some of them are, for example, chemical reactions [15], properties of particulate of matter, chemical reactions, ability to use laws and chemical theories to explain phenomena, and chemical applications in everyday life [4], basic chemistry contents [11,16-17], and acid-base chemistry [18-21]. These examples show that multiple-choice tests have long been widely used. Knowledge and competencies aspects of chemical literacy focus on chemical knowledge and cognitive-scientific inquiry skills. Both of these aspects can be assessed using multiple-choice tests.

Formally, learning outcomes of undergraduate chemistry programs are mastery of general and specific concepts and skills [22]. Ideally, these concepts and skills are achieved through lectures that apply a scientific approach oriented to solving real problems. In primary and secondary education, the scientific approach is built on five learning experiences, namely observing, asking, trying, reasoning and presenting [23]. However, the scientific approach is rarely applied in a lecture. The broad and deep range of lecture material, including general chemistry course material, makes it difficult to apply the scientific approach in the lecture. Many higher education curriculum compilers separate laboratory work from theoretical lecture, including general chemistry lectures at State University of Malang. General chemistry courses focus on comprehending content knowledge that carried out using an expository approach. This approach is considered efficient and inexpensive in delivering a large amount of information [24]. While laboratory work course focus on psychomotor skills by applying a verification or confirmatory laboratory approach $[1,25]$. These approaches lack emphasis on procedural knowledge, competency in designing inquiry, and competency in interpreting data and evidence which are important components of chemical literacy.

One topic of general chemistry course is chemical kinetics. The topic includes chemical change, the rate of chemical change and the factors which affect the rate of chemical change [26-27]. The learning outcomes for chemical kinetics topics in general chemistry course are (1) students are able to explain the reaction rate, reaction 
rate law, reaction order, molecular kinetics theory, and factors that affect the reaction rate in the level of macroscopic, sub-microscopic, and symbolic, (2) students are able to determine the reaction rate, the factors that affect the reaction rate, the reaction order and the reaction rate law of a chemical change [28]. There are some daily life phenomena of chemical changes can be learnt by students such as weathering, rusting, microbial sterilization, and combustion. Moreover, the threat of fossil fuels extinction, forest fires, climate change are social issues related to chemical change which have become public interests. In short, the environment is strongly influenced by many forms of chemical changes [29] which lead to social issues. This shows that the chemical kinetics topic is closely related to daily life phenomena that can be used to improve students' chemical literacy. Efforts to improve students' chemical literacy require a chemical literacy test instrument, in this case a chemical literacy test on chemical kinetics.

This chemical literacy test development combined the OECD [7] and Shwartz et al. [4] frameworks. The OECD [7] framework is explicit, simple and most widely used, while the Shwartz et al. [4] framework is detailed in describing properties of chemical content knowledge. The Chemical Literacy Framework used in this study can be seen in Table 1. However, this study focused on context, knowledge and competencies aspects and we excluded attitudes.

This research was conducted with two objectives. First objective was to develop and evaluate the validity and reliability of a multiple-choice chemical literacy instrument (MC-CLTI) on chemical kinetics. Second objective was to apply MC-CLTI produced in the first stage to conduct a survey on chemical literacy of firstyear chemistry students.

\section{- METHODS}

\section{Instrument Development}

The MC-CLTI construction was carried out using procedures as shown in Fig. 1. The literature review was conducted to identify the essential concepts of chemical kinetics and the context of problems that are relevant to the implemented curriculum. The identified concepts and contexts were then consulted to the experts and discussed in the Focus Group Discussion. This stage produced a concept map of chemical kinetics and four contexts of items that were relevant to the subject matters. The instrument was developed in Indonesian language. The contexts, the domains of chemical literacy, and the number of questions of chemical literacy

Table 1. Chemical literacy framework used in this study [4-7]

\begin{tabular}{ll}
\hline Aspects & Domains \\
\hline Contexts & Personal, local/national, global issues \\
\hline Knowledge & - Knowledge of chemical content [structure and nature of matter (particulate, change, \\
& thermal, and conductivity); chemical and energy changes; molecular life level (chemical \\
& structure and living system process); and the environment (global climate) [4]] \\
& - Procedural knowledge (knowledge of how scientific knowledge is produced) \\
& - Epistemic knowledge [understanding of the underlying rationale for these procedures \\
& and the justification for their use]
\end{tabular}

Muntholib et al. 


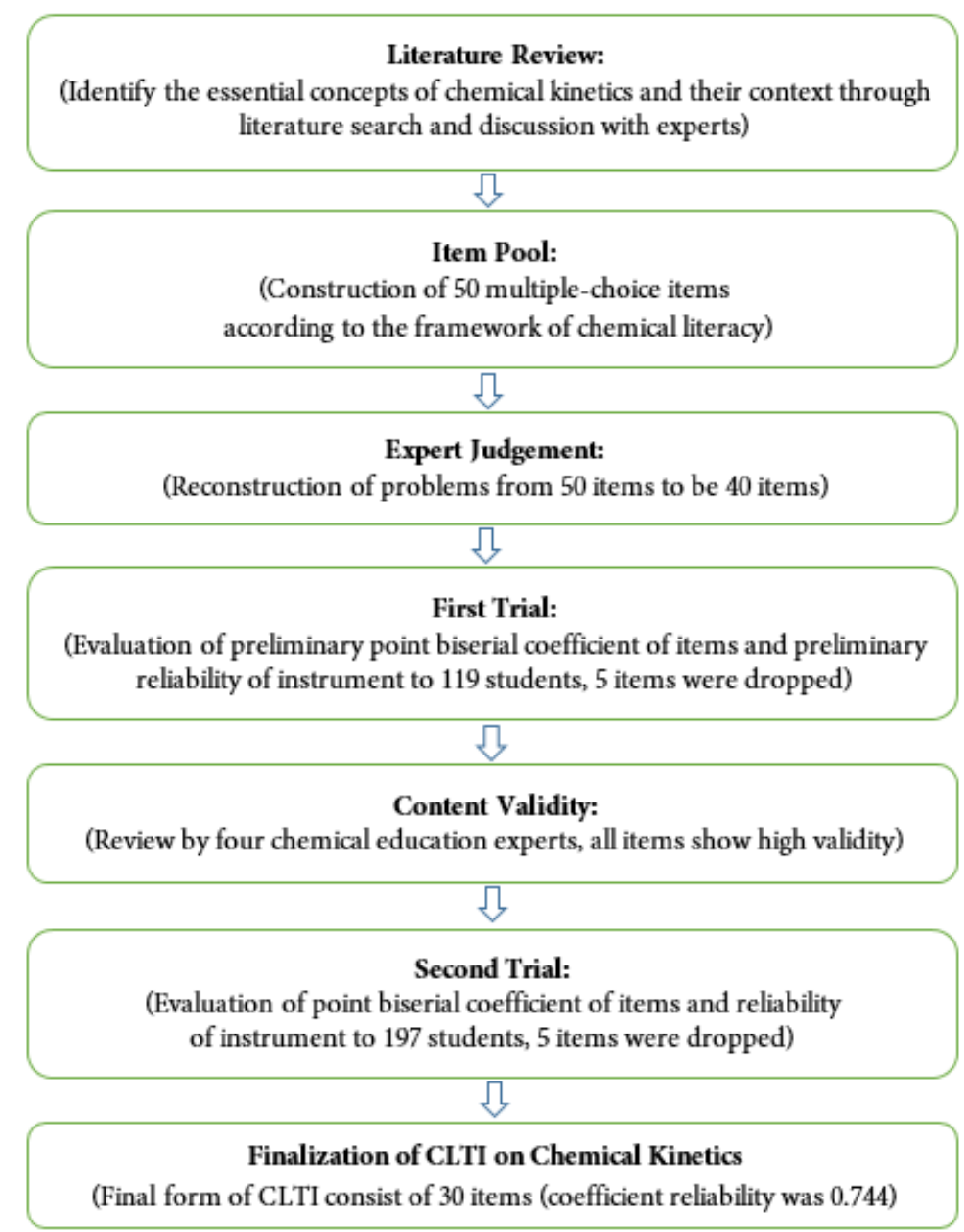

Fig 1. Development procedure of chemical literacy test instruments on chemical kinetics

instrument can be seen in Table 2 and some examples of questions can be seen in the Appendix.

The test grid and items were constructed based on the selected concepts and contexts in the previous stage. This stage produced a test grid and an initial draft of the multiple-choice chemical literacy test instrument (MCCLTI) consisting of 50 items.

Expert consultation is intended to get input regarding conformity of the instrument with the curriculum (cognitive process, depth, coverage, and representation), the framework of chemical literacy, and the suitability of the instrument with time allocation. The consultation was carried out by sending the initial draft of the MC-CLTI to the experts and followed up with Focus Group Discussion. Based on the recommendations of this group discussion, the items of the initial draft of MC-
CLTI were then reorganized into a new draft of MCCLTI consisting of 40 items.

The first trial aimed to capture the feasibility of the developed draft of MC-CLTI. The trial was conducted with 119 first-year chemistry students of regular classes. In this stage, evaluation of MC-CLTI was carried out for point biserial coefficient of items and reliability of instruments only. Point biserial coefficient measures the correlation between each item score to the total items score or the instrument total score. An item will have a high biserial coefficient if the respondents having high test scores are more likely to answer correctly than the respondents having low test scores. The value of the biserial coefficient threshold is influenced by the number of respondents, the greater number of respondents the lower the biserial coefficient threshold, 
Table 2. The context, domain of chemical literacy, and number of questions in the instrument

\begin{tabular}{|c|c|c|c|}
\hline Context & Lecture material & $\begin{array}{c}\text { Domain of chemical } \\
\text { literacy }^{\star}\end{array}$ & $\begin{array}{l}\text { Question } \\
\text { number }\end{array}$ \\
\hline \multirow{7}{*}{$\begin{array}{l}\text { Fermentation of bread } \\
\text { dough } \\
\text { (Local) }\end{array}$} & \multirow[t]{2}{*}{ Chemical reaction } & $\mathrm{EP} ; \mathrm{CK}$ & 1 \\
\hline & & EP; EK & 2 \\
\hline & \multirow[t]{2}{*}{ Reaction rate } & DI; CK & 3 \\
\hline & & DI; PK & 4 \\
\hline & \multirow[t]{3}{*}{ Law of reaction rate } & DI; PK & 5,7 \\
\hline & & ID; PK & 6 \\
\hline & & DI; EP & 8 \\
\hline \multirow{6}{*}{$\begin{array}{l}\text { Carbon dioxide and } \\
\text { life } \\
\text { (Global) }\end{array}$} & Factors affecting reaction rate & DI; CK & 9 \\
\hline & Reaction rate & DI; CK & 10,11 \\
\hline & \multirow[t]{3}{*}{ Molecular kinetic theory } & ID; CK & 12 \\
\hline & & EP; EK & 13 \\
\hline & & DI; PK & 15 \\
\hline & Reaction energy & DI; CK & 14 \\
\hline \multirow{6}{*}{$\begin{array}{l}\text { Hydrogen peroxide } \\
\text { and aseptic technology } \\
\text { (Personal) }\end{array}$} & Chemical reaction & ID; EK & 22 \\
\hline & \multirow[t]{3}{*}{ Factors affecting reaction rate } & DI; PK & $16,17,20$ \\
\hline & & DI; EK & 18 \\
\hline & & ID; EK & 19 \\
\hline & Reaction mechanism & ID; CK & 21 \\
\hline & Molecular kinetic theory & ID; CK & 23 \\
\hline \multirow{6}{*}{$\begin{array}{l}\text { Motor vehicle exhaust } \\
\text { emissions } \\
\text { (Global) }\end{array}$} & Reaction rate & ID; EK & 29 \\
\hline & \multirow[t]{3}{*}{ Factors affecting reaction rate } & ID; EK & 25,26 \\
\hline & & DI; EK & 27 \\
\hline & & DI; PK & 28 \\
\hline & Sub-microscopic representation & ID; PK & 24 \\
\hline & Half-life & ID; PK & 30 \\
\hline
\end{tabular}

${ }^{{ }^{*} \mathrm{P}}=$ Explain Phenomena Scientifically; DI $=$ Design Scientific Inquiry; ID = Interpret Data and Evidence Scientifically; CK = Content Knowledge; PK = Procedural Knowledge; EK = Epistemic Knowledge

but in general the acceptable value of the biserial coefficient threshold of items is 0.2 [30-31]. The analysis shows that 10 out of 40 items were not valid. Five of the invalid items, in which the value of their biserial coefficient were near to the threshold, were revised. While five other items with value of their biserial coefficient were far from the threshold were deleted. Thus, the final draft of MC-CLTI, which was further processed, consist of 35 items.

Reliability illustrates the stability and consistency score of an instrument [32]. A stable instrument will produce nearly the same results when it is used to measure the same object at different times [33]. An instrument is said to be consistent if an individual answers two or more closely related questions using the same way. The reliability of this research instrument was calculated using Cronbach's Alpha. A useful rule of thumb is that reliability of achievement tests for research purposes should be at least 0.70 and preferably higher [34]. However, some publications can accept 
instruments with a reliability value of 0.45 [35]. Several leading science education journals also accept research instruments with Cronbach's alpha values of less than 0.7 [36]. Calculation showed that Cronbach's alpha of this "initial draft of instrument" was 0.63 . This reliability coefficient was below the value of achievement tests for research purposes, e.g. 0.70 [34], but can be accepted by the leading science education journal [36].

Validity is defined as the extent to which an instrument measures the magnitude of the construct to measure [33]. There are many kinds of validity, but this study evaluates content validity only. Content validity is a judgment of how appropriate the items seem to a panel of experts in the subject matter [14]. Content validity evaluation was carried out using the Index of ItemsObjectives Congruence (IOC), which is the ratio between the number of validators which states that an item is valid to the number of all validators [37]. In the IOC process, experts assess each item with criteria (1) the suitability of items with the subject matter to test, (2) the suitability of each items with their respective indicators, (3) the truth of content knowledge, and (4) clarity of language to use.

Evaluation of content validity involved four experts. In this study, the validity of the items was determined based on the average score given by the validators with interval class criteria. The size of the interval class was determined by dividing the data range by the number of interval classes. The data range of this study was the highest score (4) - the lowest score $(1)=3$, while the number of interval classes $=4$. This means that the size of the interval class was equal to data range (3) divided by the number of interval classes (4), i.e., $=3 / 4$. Therefore, the interval class range (ICR) used in this study was very high $(\mathrm{VH})$ if $4 \geq \mathrm{ICR} \geq 3.25$; high $(\mathrm{H})$ if $3.25>\mathrm{ICR} \geq 2.5$; low (L) if $2.5>\mathrm{ICR} \geq 1.75$; and very low (VL) if $1.75>\mathrm{ICR} \geq 1.0$.

Evaluation to the preliminary draft of MC-CLTI showed that the assessment instrument had not been satisfactory. Ten out of forty items of the instrument were invalid with the reliability coefficient was below the acceptable value. Therefore, the assessment test draft was revised and refined. The second trial was conducted to 197 first-year chemistry students, both regular and bilingual classes. The evaluation covered construct validity, index of difficulty, index of discriminant, and point biserial coefficient.

The finalization of MC-CLTI on chemical kinetics was done by sorting and selecting items that were in accordance with (1) the chemical literacy framework of research, (2) standard content and construct validity of instruments, (3) values of difficulty index, discrimination index, and point biserial coefficient of items, (4) minimum value of instrument reliability, and (5) aesthetic and mathematical calculation aspects. Final form of chemical literacy instrument of chemical kinetics consist of 30 items with Cronbach reliability was 0.744 .

\section{Survey on Students' Chemical Literacy}

Respondents of this study were 71 first-year chemistry students of the bilingual class in Chemistry Department, The Faculty of Mathematics and Natural Sciences, State University of Malang of the academic year of 2017/2018. Bilingual class is designed to produce graduates who are capable of working in international institutions. Bilingual class students are selected from new students with two kind of tests, namely the field of study and English tests. They were 37 students of Chemistry Program and 34 students of Chemistry Education Programs. The students come from bilingual classes who have specific characteristics: (a) having good proficiency in English, and (b) having above academic achievement compared to regular classes. The general chemistry course was delivered mainly in English especially for teaching materials and the rest was in Indonesian language.

The data collection was carried out as midterm examinations after students experienced lectures on chemical kinetics conducted by using the expository approach. The data analysis was carried out by calculating the percentage of respondents' response, both at the level of chemical literacy and at the level of its domains.

\section{- RESULTS AND DISCUSSION}

\section{Development Results of MC-CLTI}

The second draft of MC-CLTI consisted of 35 items. The MC-CLTI draft was then evaluated to find 
out the content and construct validity, difficulty index, discrimination index, point biserial coefficients, and reliability. The following descriptions describe the results of each evaluation.

\section{Description of second trial results}

The second trial of the second draft of the MC-CLTI on chemical kinetics was carried out with 197 chemistry students of the State University of Malang. Among the research subjects, 98 were Chemistry Education students and 99 were Chemistry students. All students involved in this study have completed the chemistry kinetics of Basic Chemistry II. The results of the trial are presented in Table 3.

\section{Validity of instrument}

Evaluation of validity was carried out using two types of validity, content validity.

Content validity. The validity was analyzed based on judgment of four experts in chemistry education. They justified whether each item was both communicative and corresponds to the concept measured in the specification grid. In addition to providing judgment, experts also provided suggestion for revision, both language and content aspects. The suggesting items were discussed with the expert and then revised.
Item analysis. For item analysis, the second draft of MC-CLTI consisting of 35 valid items, justified by expert and revised was trialed with 197 first-year chemistry students. The results of the MC-CLTI trial were then analyzed to know (1) items difficulty index, (2) items discrimination index and (3) point biserial coefficient.

Items difficulty index (P). The difficulty index shows how difficult an item is solved by respondents. Determination of the difficulty index was done by comparing the number of respondents who answered correctly an item with the number of total respondents. The value of difficulty index $(\mathrm{P})$ varied from 0.0 to 1.0. An item was considered too easy if $\mathrm{P}>0.9$, moderate if $0.9<\mathrm{P}<0.3$, and too difficult if $\mathrm{P}<0.3$ [14]. Fig. 2 showed the index of difficulty of items of MC-CLTI. The figure showed that 32 out of 35 items of MC-CLTI had medium difficulty index $(0.30 \leq \mathrm{P} \leq 0.90)$ while 3 other items had a high difficulty index $(\mathrm{P}>0.3)$. The average value of MC-CLTI items difficulty index was 0.58 (medium). This value did not too far from the value of ideal average difficulty index, i.e., 0.50 . High proportion of items having moderate difficulty index indicates that items of MC-CLTI were normally distributed. Therefore MC-CLTI can be used as a data collection instrument.

Table 3. Overall result of instrument trial for student groups

\begin{tabular}{lccccc}
\hline \multicolumn{1}{c}{ Group } & N & $\begin{array}{c}\text { Standard } \\
\text { deviation }\end{array}$ & Highest score & Lowest score & Average score \\
\hline All & 197 & 4.98 & 31 & 10 & 20.16 \\
Chemical Education Program & 98 & 4.95 & 31 & 10 & 21.17 \\
Chemistry Program & 99 & 4.82 & 31 & 10 & 19.15 \\
\hline
\end{tabular}

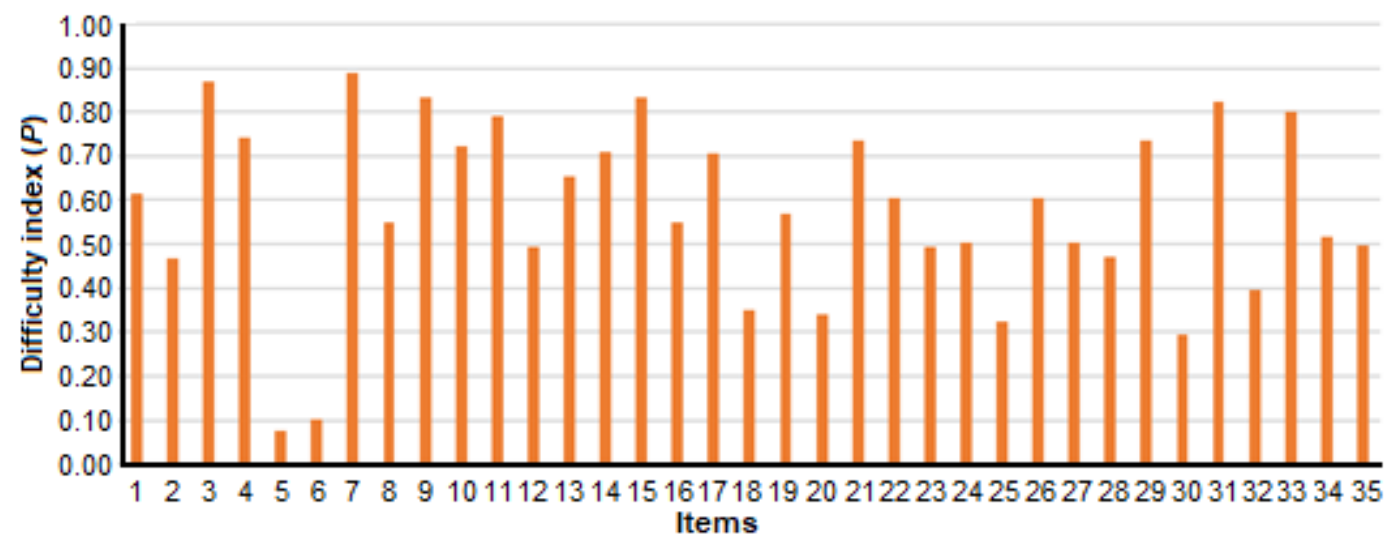

Fig 2. Difficulty index of items 
Item discrimination index (D). The discrimination index (D) shows the ability of an item to distinguish between more competent respondent from less competent one. The discrimination index of an item is determined based on score of $25 \%$ upper group and $25 \%$ lower group respondents [14]. The index is determined by using equation " $D=p(U G)-p(L G)$ ", in which $p(U G)$ and $p(L G)$ are the proportions of the correct answers of the upper and lower groups respectively. $\mathrm{D}$ values range between +1.0 (maximum) and -1.0 (minimum). $\mathrm{D}=+1.0$ if all of upper group respondents give the correct answer to an item and all of lower group respondents give the wrong answer. On the contrary, $\mathrm{D}=-1.0$ if all of the upper group respondents give the wrong answer and all of the lower group respondents give the right answer. The discrimination index of an item is considered to be good if the $\mathrm{D}$ value of the item is greater than 0.30 [30-31]. The discrimination index of 35 items of MC-CLTI were 26 greater than $0.3,4$ items between 0.2 to 0.3 , and 5 items less than 0.2. The average discrimination index for all MC-CLTI items was 0.37 . Items having discrimination index slightly lower than 0.30 can be used in formative test, because this test is not designed for grading [38]. Items number 3, 27, 30 and 33 having discrimination indexes above of 0.20 were used in MC-CLTI. Items number $5,6,7,8$, and 26 having discrimination index lower than 0.20 were removed. Therefore, based on the analysis of discrimination index, 30 items of chemical kinetics can be used in MC-CLTI.

Point biserial coefficient. Point biserial coefficient measures the correlation between the scores of each item and the score of the overall items of an instrument. High value of point biserial coefficient indicates that respondents who answered an item correctly had a higher test score. Acceptable value of point biserial coefficient of an item is 0.2 [30-31]. The point biserial coefficient value of 35 items of MC-CLTI were 31 items above of $0.20,3$ items less than 0.20 (problems $5,7,8$ ), and 1 item negative (problem 6). Items having point biserial coefficient below 0.2 were removed from instrument of MC-CLTI.

The above analysis showed that 5 items having a low point biserial coefficient also had a low discrimination index. Based on these two parameters, 5 items were invalid, and 30 other items were valid. The invalid items were number $5,6,7,8$, and 26 . Based on the consideration of the item discrimination index, the items point biserial coefficient, the items proportion of each chemical literacy domain, aesthetic, and mathematical calculations aspects, 30 items were used in MC-CLTI instrument. Thus, the final form of MC-CLTI consists of 30 items representing all domains of chemical literacy (example of the problems is supplemented in the Appendix).

Reliability of test instrument. The reliability of the research instrument was determined based on the Cronbach's Alpha coefficient. Analysis of instrument reliability was carried out using the SPSS for Windows program. Cronbach Alpha coefficient of MC-CLTI instrument was 0.744 . This value was the above of the acceptable limit of instrument reliability, i.e. 0.5 [39] or $0.7[40]$.

\section{Students' Chemical Literacy on Chemical Kinetics}

The final MC-CLTI instrument which consisted of 30 items and had reliability of 0.744 were used to survey students' chemical literacy on chemical kinetics. The test was delivered to 71 first-year chemistry students who enrolled in General Chemistry courses after they learned a chemical kinetics topic in an expository lecture. The result of survey on these students were presented in Table 4.

Table 4 showed that the range of students' MCCLTI test scores was 30.00 to 93.33 with an average score was 63.24. Even though students were familiar with multiple-choice tests, they were still unfamiliar with the type of questions addressing on the chemical literacy test.

Table 4. The average score of chemical literacy on the chemical kinetics of first year chemistry students

\begin{tabular}{cccccc}
\hline $\mathbf{N}$ & Total items & The lowest score & The highest score & Average score & Deviation standard \\
\hline 71 & 30 & $9(30)$ & $28(93.33)$ & $18.97(63.24)^{*}$ & 4.23 \\
$*$ Figure in the parentheses is a score on a scale of 100 & &
\end{tabular}

Muntholib et al. 
Students normally received an assessment on content and epistemic knowledges using essay or multiple-choice types. While the chemical literacy test asked for more than content knowledge and epistemic knowledge, such as procedural knowledge and ability to explain phenomena, design scientific inquiry, and interpret evidence scientifically. In addition, the assessment of content knowledge focused more on understanding of concepts while the assessment of chemical literacy focused more on reasoning. Therefore, the students' average score of 63.24 was considered a satisfactory achievement.

The average score of respondents' chemical literacy of this study was in the range of the average score of respondents' chemical literacy reported by several previous studies. The average chemical literacy score on acid base of first-year chemistry students who experienced argumentation immersed in inquiry-based learning was 62.25 [9], the average score of chemical literacy on thermochemical and thermodynamics concepts of first-year chemistry students who experienced expository instruction was 59.53, and those who experienced in a context-based instruction was 73.27 [2]. This finding showed that the learning conditions of this research subject are not much different from the learning conditions of the research subjects of Cigdemoglu and Geban [2] and Cigdemoglu et al. [9].

Regardless the results of this study were close to the results of studies reported by previous researchers, the use of multiple-choice type instrument had several advantages. First, multiple-choice type test were easy to use and to analyze for very large respondents [14]. Second, the use of chemical literacy tests that focus on reasoning did not reduce the students' achievement scores compared to the use of conventional test that focused on content knowledge and epistemic knowledge. Third, the use of chemical literacy test encouraged students to develop reasoning ability. However, since this study didn't assess the attitude aspect of chemical literacy, it could be considered the weakness of this instrument for fully justifying the chemically literate students. For the future research, it is necessarily to incorporate the attitude aspect into this type of instrument.
The four aspects of chemical literacy (context, knowledge, competency, and attitudes) are interrelated each other. This research focused on two aspects of chemical literacy only, namely scientific knowledge and competency. This choice was based on two considerations. First, the research instrument was designed for university students with the content knowledge of chemical kinetics. University students naturally have had global information, while content knowledge of chemical kinetics is deep and specific. Therefore, classification of the context of problems into personal, local and global becomes less relevant. Second, attitudes towards science measured using a student questionnaire [7]. Therefore, the measurement of attitudes towards science can be carried out separately from other aspects of chemical literacy.

From the perspective of the scientific knowledge aspect, chemical literacy is divided into three domains, namely the domain of chemical content knowledge, procedural knowledge (knowledge of how scientific knowledge is produced), and epistemic knowledge (understanding of the underlying reasons for the use of a scientific procedure and its justification) (Table 1). Whereas from perspective of competency aspect, chemical literacy is also divided into three domains, namely explaining phenomena scientifically, evaluating and designing scientific inquiry, and interpreting data and evidence scientifically. Table 5 shows the results of the analysis of the domain of chemical literacy from the perspective of scientific knowledge and competencies.

Table 5 shows that the average scores of chemical literacy domains of first-year students from the lowest to the highest are epistemic knowledge (52.33), chemistry content knowledge (56.00), explaining phenomena scientifically (56.00), interpreting scientific data and evidence scientifically (59.75), evaluating and designing scientific inquiry (66.67), and procedural knowledge (72.21). This result is quite surprising because the respondents of this research experienced instruction carried out using the expository approach. In expository approach lecturer transmits knowledge to the students [41-42], lecturer dominate the presentation of lessons and use strategies that include lectures, demonstrations, 
Table 5. Respondents' score of chemical literacy domains

\begin{tabular}{lcccr}
\hline & Number of items & Lowest score & Highest score & Average score \\
\hline Domains of knowledge aspect & & & & \\
1. Chemical Content Knowledge & 10 & $1(10.00)$ & $9(90.00)$ & $5.60(56.00)$ \\
2. Procedural Knowledge & 14 & $4(28.57)$ & $14(100.00)$ & $10.11(72.21)$ \\
3. Epistemic Knowledge & 6 & $0(0.00)$ & $6(100.00)$ & $3.14(52.33)$ \\
Domains of competencies aspect & & & & \\
1. Explain phenomena scientifically & 3 & $0(0.00)$ & $3(100.00)$ & $1.68(56.00)$ \\
2. Evaluate and design scientific inquiry & 15 & $3(20.00)$ & $14(93.33)$ & $10.00(66.67)$ \\
3. Interpret data and evidence scientifically & 12 & $1(8.33)$ & $11(91.67)$ & $7.17(59.75)$ \\
\hline
\end{tabular}

${ }^{\star}$ The numbers in parentheses are scores scaled to 100

and videos. This means that the expository instruction focuses on content knowledge. Thus, the students' chemical content knowledge domain score should be better than the other domain score of chemical literacy. However, the survey showed that the domain scores of evaluating scientific inquiry and procedural knowledge were better than the domain score of chemical content knowledge. This can be caused by: (1) procedural knowledge and ability to design scientific inquiry are general and reasonable, while epistemic and content knowledge are in-depth and requires perseverance in learning, (2) when respondents of this study were school students, they have experienced learning with a scientific inquiry approach, and (3) the respondents were selected students (bilingual classes) having abilities better than regular class. The scientific inquiry approach is an instructional approach applying five learning experiences, namely observe, explore, collect data, elaborate, and communicate [23]. The respondents' high ability to reason and their learning experience when they were school students may cover the low quality of expository instruction they received in the university. Therefore, their low achievement of chemical content knowledge has little influence only to other domains of chemical literacy that require more reasoning abilities such as domain "to evaluate and design scientific inquiry" and domain "to explain phenomena scientifically". The students' reasoning abilities and the learning experience they received when they were schools' student can mask the weakness of the expository approach implemented in most Indonesian university. Therefore, the weak of students' chemical content knowledge has little effect to other domains of chemical literacy, especially those requiring reasoning abilities.

Epistemic knowledge includes understanding the functions of questions, observations, theories, hypotheses, models, and arguments in the science process; introduction to the forms of scientific inquiry; and understanding of the role of peer review in the validation of knowledge [7]. One understanding of epistemic knowledge was assessed using item number \#13 of MC-CLTI (See Appendix). The number of respondents answering this item correctly is $76.06 \%$. To be able to answer this question respondents need to understand how the temperature increases the rate of reaction. The effect of temperature on the reaction rate is the main subject matter of the topic of the reaction rate. Increasing of temperature increases the kinetic energy of the particle, the frequency of collision, and the proportion of particles exceeding activation energy [2627]. Consequently, an increasing of temperature increases the rate of reaction. This knowledge is widely explained in the textbooks and in lectures. Therefore, this subject matter is generally well understood by students.

Chemical content knowledge or "knowledge of chemical content" is factual and conceptual knowledge (concepts, ideas, laws, principles and theories) about natural phenomena that have been accepted as truth [7]. One of chemical content knowledge was assessed using 
item number \# 25 of MC-CLTI (See Appendix). This item was only answered correctly by $19.72 \%$ of respondents. To answer this question, respondents need an essential understanding of particulate of matter. Matter can be represented in three levels of representation, namely macroscopic, submicroscopic, and symbolic [43-44]. The students who have essential understanding can change representations of matter from one representation to another. To answer this question, students should change the matter representation from symbolic $\left(\mathrm{NO}\right.$ and $\left.\mathrm{O}_{2}\right)$ to submicroscopic (particulates) and then to macroscopic (pressure or concentration). The low percentage of respondents who correctly answered this item indicates that they did not understand the relationship between concentration and pressure at the submicroscopic level. In other words, the research respondents' understanding on chemical content knowledge especially in particulate representation of matter was not satisfactory.

Ability to explain phenomena scientifically, according to the PISA perspective, includes recognizing, offering, and evaluating explanations of various natural phenomena [7]. The ability to explain phenomena scientifically, one of them, was assessed using item number \#2 of MC-CLTI (See Appendix). This item was correctly answered by $54.93 \%$ of respondents. To be able to answer this problem, the respondent should understand why the bread dough expands, what gas does cause the bread to expand, and where the gas comes from. The enlargement of bread dough is caused by cavities of $\mathrm{CO}_{2}$ gas produced by alcohol fermentation. Actually, this explanation is available in the text above of the items. However, students have not connected the abstract concept of $\mathrm{CO}_{2}$ gas with a concrete phenomenon of bread dough volume. This type of difficulty has been revealed by many previous researchers, for example when iron melted its atoms did not change but the size of its atoms enlarged [45]. Therefore, students have difficulties to solve the problem.

Interpreting data is a core activity of scientific inquiry [7]. Data interpretation starts from looking for patterns, making simple tables, and making graphically visualizations such as circle diagrams, bar graphs, scatter diagrams, or Venn diagrams. However, it is not appropriate to assess students' ability to interpret data only by searching for patterns, creating tables and developing graphic visualizations. Interpreting data and evidence also means making meaning to the resulting conclusions. MC-CLTI assesses respondent's ability to interpret the data and evidence, one of them with item number \#26 (See Appendix). This question requires respondents to read the graph and making meaning to the graph as claim. This item was correctly answered by $85.92 \%$ of respondents. This question is quite simple, only asking students to make claims according to collected data. However, this problem is very important. Making claims is an important part of competency to design scientific inquiry [7] and scientific arguments [46] as well as the highest level of cognitive processes (creating) in the revised taxonomy assessment of Bloom [47].

Ability to evaluate and to design scientific inquiry, according to the PISA perspective, is the ability to describe and appraise scientific investigations and propose ways to answer questions scientifically [7]. Item number \#11 of MC-CLTI (See Appendix) is an example of problem used to assess students' ability to evaluate and design scientific inquiry. This item is correctly answered by $90.14 \%$ of respondents. Actually, this problem is complex enough. To be able to answer this question, respondents have to identify independent variables, dependent variables, control variables, how to vary the surface area, how to determine or measure time of reaction, and how to control the control variables. However, respondents of the research have learned chemical kinetics twice, in the second semester of $11^{\text {th }}$ grade and in the second semester of first year. Factors that influence the reaction rate are the main subtopic of chemical kinetics. Therefore, students well understand of the subtopic and its logical thinking. Even the concept of surface area influences the rate of reaction and variations of surface area can be made by varying the size of the reactant granules have become part of the respondents' common sense. Therefore, students can answer this problem easily.

Procedural knowledge is knowledge about procedure used by scientists to build scientific 
knowledge [7]. Procedural knowledge is knowledge about practices and concepts that underlie empirical inquiry such as repetition of measurements to reduce errors, control variables, and procedures in processing, representing, and communicating data. One understanding of procedural knowledge was assessed by using item number \# 9 of MC-CLTI (See Appendix). This question was answered correctly by $66.20 \%$ of respondents. To answer this question the research subject requires an understanding of various research variables including independent variables, dependent variables, and control variables. In this question, students examine effect of surface area on the reaction rate of $\mathrm{CaCO}_{3}(s)$ reacting with $\mathrm{HCl}(a q)$. Independent variable of the research is particle size of $\mathrm{CaCO}_{3}(s)$, dependent variable is reaction time or rate of reaction, and control variables are concentration of $\mathrm{HCl}$ and temperature of reaction. Expository instruction actually gives less attention to understanding the various variables of investigation. However, results of this study indicated that respondents' understanding on procedural knowledge was satisfactory. This finding can be explained in two ways. First, student learning experiences when they were high school students that received instruction using scientific approach. Second, respondents of this study were selected students grouped into bilingual classes. They have better performance compared with the average students. Therefore, the research respondents can choose the right answers among the available options based on their previous experience and logical thinking.

\section{- CONCLUSION}

The knowledge and competency aspects of MCCLTI on chemical kinetics consists of 30 valid items with Cronbach's Alpha coefficient reliability of 0.744 . This reliability coefficient is above the value of achievement tests for research [34] and can be accepted by leading science education journals [36]. Therefore, this test can be used to assess students' chemical literacy.

Survey shows that first year university students' scores on MC-CLTI test ranged from 30.00 to 93.33 with average score was 63.24. This score was in the range of students' chemical literacy average scores reported by previous researchers [2,9]. This result indicated that bilingual students seem no need a specific learning strategy to achieve satisfactory chemical literacy. At the level of chemical literacy domains, the average scores of first-year students from the lowest to the highest are epistemic knowledge (52.33), chemistry content knowledge (56.00), explaining phenomena scientifically (56.00), interpreting scientific data and evidence scientifically (59.75), evaluating and designing scientific inquiry (66.67), and procedural knowledge (72.21). These results indicated that for selected students, low and medium cognitive demand (understanding and applying scientific knowledge) are more difficult than high cognitive demand (analyse complex information or reasoning) [7].

\section{- IMPLICATIONS FOR TEACHING AND EDUCATIONAL RESEARCH}

This study has the following important implications for chemistry education: (1) multiplechoice chemical literacy test can be used in chemistry education so that they need to be developed, although the attitude aspect could be assessed separately; (2) for bilingual (selected) students, chemical literacy instructions didn't seem to be taught using specific strategies, it can be sufficiently embedded in conventional learning strategies, however for ordinary students they might still need an innovative instruction directed towards achieving scientific literacy; (3) although it is not the sole objective of learning, scientific knowledge should be the focus of learning; (4) chemical literacy tests should be used to assess student achievement so that they are trained to solve daily life problems scientifically; and investigations on teaching strategies which are effective to improve students' chemical literacy needs to be done, for classes with various level of abilities, especially medium or low level of abilities.

\section{- REFERENCES}

[1] Barnea, N., Dori, Y.J., and Hofstein, A., 2010, Development and implementation of inquiry-based and computerized-based laboratories: Reforming 
high school chemistry in Israel, Chem. Educ. Res. Pract., 11 (3), 218-228.

[2] Cigdemoglu, C., and Geban, O., 2015, Improving students' chemical literacy levels on thermochemical and thermodynamics concepts through a contextbased approach, Chem. Educ. Res. Pract., 16 (2), 302317.

[3] DeBoer, G.E., 2000, Scientific literacy: Another look at its historical and contemporary meanings and its relationship to science education reform, J. Res. Sci. Teach., 37 (6), 582-601.

[4] Shwartz, Y., Ben-Zvi, R., and Hofstein, A., 2006, The use of scientific literacy taxonomy for assessing the development of chemical literacy among high-school students, Chem. Educ. Res. Pract., 7 (4), 203-225.

[5] Singer, S.R., Hilton, M.L., and Scheingruber, H.A., 2005, America's Lab Report: Investigations in High School Science, National Research Council, National Academies Press, Washington, D.C.

[6] Bond, D., 1989, In pursuit of chemical literacy: A place for chemical reactions, J. Chem. Educ., 66 (2), 157.

[7] OECD, 2016, PISA 2015 Assessment and Analytical Framework: Science, Reading, Mathematic, Financial Literacy and Collaborative Problem Solving, OECD Publishing, Paris.

[8] Ratcliffe, M., and Millar, R., 2009, Teaching for understanding of science in context: Evidence from the pilot trials of the Twenty First Century Science courses, J. Res. Sci. Teach., 46 (8), 945-959.

[9] Cigdemoglu, C., Arslan, H.O., and Cam, A., 2017, Argumentation to foster pre-service science teachers' knowledge, competency, and attitude on the domains of chemical literacy of acids and bases, Chem. Educ. Res. Pract., 18 (2), 288-303.

[10] Shwartz, Y., Ben-Zvi, R., and Hofstein, A., 2005, The importance of involving high-school chemistry teachers in the process of defining the operational meaning of 'chemical literacy', Int. J. Sci. Educ., 27 (3), 323-344.

[11] Thummathong, R., and Thathong, K., 2016, Construction of a chemical literacy test for engineering students, J. Turk. Sci. Educ., 13 (3), 185-198.

[12] Chang, S.N., and Chiu, M.H., 2005, The development of authentic assessments to investigate ninth graders' scientific literacy: In the case of scientific cognition concerning the concepts of chemistry and physics, Int. J. Sci. Math. Educ., 3 (1), 117-140.

[13] OECD, 2006, Assessing scientific, reading and mathematical literacy: a framework for PISA 2006, OECD Publishing, Paris.

[14] Wattanakasiwich, P., Taleab, P., Sharma, M.D., and Johnston, I.D., 2013, Development and Implementation of a Conceptual Survey in Thermodynamics, Int. J. Innovation Sci. Math. Educ., 21 (1), 29-53.

[15] Chandrasegaran, A.L., Treagust, D.F., and Mocerino, M., 2007, The development of a two-tier multiple-choice diagnostic instrument for evaluating secondary school students' ability to describe and explain chemical reactions using multiple levels of representation, Chem. Educ. Res. Pract., 8 (3), 293-307.

[16] Cloonan, C.A., and Hutchinson, J.S., 2011, A chemistry concept reasoning test, Chem. Educ. Res. Pract., 12 (2), 205-209.

[17] Mutlu, A., and Şeşen, B.A., 2016, Evaluating of preservice science teachers' understanding of general chemistry concepts by using two tier diagnostic test, J. Baltic Sci. Educ., 15 (1), 79-96.

[18] Artdej, R., Ratanaroutai, T., Coll, R.K., and Thongpanchang, T., 2010, Thai grade 11 students' alternative conceptions for acid-base chemistry, Res. Sci. Technol. Educ., 28 (2), 167-183.

[19] Demircioglu, G., Ayas, A., and Demircioglu, H., 2005, Conceptual change achieved through a new teaching program on acids and bases, Chem. Educ. Res. Pract., 6 (1), 36-51.

[20] Damanhuri, M.I.M., Treagust, D.F., Won, M., and Chandrasegaran, A.L., 2016, High school students' understanding of acid-base concepts: An ongoing challenge for teachers, Int. J. Environ. Sci. Educ., 11 (1), 9-27. 
[21] Muntholib, Mayangsari, J., Pratiwi, Y.N., Muchson, Joharnawan, R., Yahmin, and Rahayu, S., 2017, Development of Simple Multiple-Choice Diagnostic Test of Acid-Base Concepts to Identify Students Alternative Conceptions, Proceedings of the $1^{\text {st }}$ Annual International Conference on Mathematics, Science, and Education (ICoMSE 2017), Malang, Indonesia.

[22] Ministry of Research, Technology and Higher Education, 2015, Regulation of Ministry of Research, Technology and Higher Education Number 44 year 2015: Process Standard for Higher Education, Ministry of Research, Technology and Higher Education, Jakarta.

[23] Ministry of Education and Culture, 2016, Regulation of Minister of Education and Culture Number 22 year 2016: Process Standard for Primary and Secondary Education, Ministry of Education and Culture, Jakarta.

[24] Sunal, D.W., Wright, E., and Day, J.B., Eds., 2004, Reform in Undergraduate Science Teaching for the $21^{\text {st }}$ Century, Information Age Publishing, Greenwich.

[25] Dudu, W.T., 2014, Exploring South African high school teachers' conceptions of the nature of scientific inquiry: A case study, S. Afr. J. Educ., 34 (1), 1-19.

[26] Chang, R., and Goldsby, K.A., 2016, Chemistry, $12^{\text {th }}$ ed., McGraw-Hill Education, New York.

[27] McMurry, J., Fay, R.C., and Robinson, J.K., 2015, Chemistry, $7^{\text {th }}$ ed., Pearson Education Limited, England.

[28] Faculty of Mathematics and Natural Science, State University of Malang, 2018, Chemistry Department Catalog Year 2018, Malang, Indonesia.

[29] Gilbert, J.K., and Treagust, D.F., 2009, "Introduction: Macro, Submicro and Symbolic Representations and the Relationship Between Them: Key Models in Chemical Education" in Multiple Representations in Chemical Education, vol. 4, Eds. Gilbert, J.K., and Treagust, D., Springer, Dordrecht, Netherlands, 1-8.

[30] Ding, L., and Beichner, R., 2009, Approaches to data analysis of multiple-choice questions, Phys. Rev. Spec. Top. Phys. Educ. Res., 5 (2), 020103.

[31] Wuttiprom, S., Sharma, M.D., Johnston, I.D., Chitaree, R., and Soankwan, C., 2009, Development and use of a conceptual survey in introductory quantum physics, Int. J. Sci. Educ., 31 (5), 631-654.

[32] Bybee, R.W., Taylor, J.A., Gardner, A., Van Scotter, P., Powell, J.C., Westbrook, A., and Landes, N., 2006, BSCS 5E Instructional Model: Origins and Effectiveness, A Report Prepared for the Office of Science Education, National Institutes of Health, Colorado Springs, Colorado.

[33] Kimberlin, C.L., and Winterstein, A.G., 2008, Validity and reliability of measurement instruments used in research, Am. J. Health Syst. Pharm., 65 (23), 2276-2284.

[34] Fraenkel, J.R., and Wallen, N.E., 2009, How to Design and Evaluate Research in Education, $7^{\text {th }}$ ed., McGraw-Hill, New York.

[35] van Griethuijsen, R.A.L.F., van Eijck, M.W., Haste, H., den Brok, P.J., Skinner N.C., Mansour, N., Gencer, A.S., and BouJaoude, S., 2015, Global patterns in students' views of science and interest in science, Res. Sci. Educ., 45 (4), 581-603.

[36] Taber, K.S., 2018, The use of Cronbach's alpha when developing and reporting research instruments in science education, Res. Sci. Educ., 48 (6), 1273-1296.

[37] Sireci, S.G., 1998, Gathering and analyzing content validity data, Educ. Assess., 5 (4), 299-321.

[38] Adams, W.K., and Wieman, C.E., 2011, Development and validation of instruments to measure learning of expert-like thinking, Int. J. Sci. Educ., 33 (9), 1289-1312.

[39] Salvucci, S., Walter, E., Conley, V., Fink, S., and Saba, M., 1997, Measurement Error Studies at the National Center for Education Statistics, U.S. Department of Education, New York.

[40] Gormally, C., Brickman, P., Hallar, B., and Armstrong, N., 2009, Effects of inquiry-based learning on students' science literacy skills and confidence, IJ-SoTL, 3 (2), 16.

[41] Çetin, A., and Özdemir, Ö.F., 2018, Mode-method interaction: the role of teaching methods on the effect of instructional modes on achievements, science process skills, and attitudes towards physics, Eurasia J. Math. Sci. Technol. Educ., 14 (5), 18151826. 
[42] Sigler, E.A., and Saam, J., 2012, Constructivist or expository instructional approaches: Does instruction have an effect on the accuracy of Judgment of Learning (JOL)?, JoSoTL, 7 (2), 22-31.

[43] Johnstone, A.H., 1991, Why is science difficult to learn? Things are seldom what they seem, J. Comput. Assist. Learn., 7 (2), 75-83.

[44] Taber, K.S., 2013, Revisiting the chemistry triplet: Drawing upon the nature of chemical knowledge and the psychology of learning to inform chemistry education, Chem. Educ. Res. Pract., 14 (2), 156-168.

[45] Kikas, E., 2004, Teachers' conceptions and misconceptions concerning three natural phenomena, J. Res. Sci. Teach., 41 (5), 432-448.

[46] Walker, J.P., and Sampson, V., 2013, Learning to argue and arguing to learn: argument-driven inquiry as a way to help undergraduate chemistry students learn how to construct arguments and engage in argumentation during a laboratory course, J. Res. Sci. Teach., 50 (5), 561-596.

[47] Anderson, L.W., Krathwohl, D.R., Airasian, P.W., Cruikshank, K.A., Mayer, R.E., Pintrich P.R., Raths, J., and Wittock, M.C., 2001, A Taxonomy for Learning, Teaching, and Assessing: A Revision of Bloom's Taxonomy of Educational Objectives, Longman, New York. 